\title{
IMPLEMENTASI PRODUK LAYANAN PEMBIAYAAN SYARIAH BERBASIS FINANCIAL TECHNOLOGY (STUDI KASUS PT. INVESTREE)
}

\author{
Nazela Fardana ${ }^{1}$ \\ ${ }^{1}$ Prodi Ekonomi Syariah Fakultas Ekonomi dan Bisnis Islam UIN Sunan Ampel Surabaya, Jl. \\ Ahmad Yani 117 Surabaya \\ Email: vysanda082@gmail.com \\ Nisha Nor Rahmawati ${ }^{2}$, \\ ${ }^{1}$ Prodi Ekonomi Syariah Fakultas Ekonomi dan Bisnis Islam UIN Sunan Ampel Surabaya, Jl. \\ Ahmad Yani 117 Surabaya \\ Nur Rohmayaty ${ }^{3}$, \\ ${ }^{1}$ Prodi Ekonomi Syariah Fakultas Ekonomi dan Bisnis Islam UIN Sunan Ampel Surabaya, Jl. \\ Ahmad Yani 117 Surabaya \\ Pravita Salbia Nurmanda ${ }^{4}$ \\ ${ }^{1}$ Prodi Ekonomi Syariah Fakultas Ekonomi dan Bisnis Islam UIN Sunan Ampel Surabaya, Jl. \\ Ahmad Yani 117 Surabaya
}

\begin{abstract}
Now financing or lending service products (crowdfunding and $P 2 P$ Lending) infintech have been present by implementing sharia principles which refer to the DSN-MUI fatwa which is the benchmark and OJK and DPS as supervisors in their development strategy, such as the start-up Investree which acts as a a platform offering solutions in the world of online business to SMEs with the aim of strengthening the country's economy. Investree startup also always improves its performance so that it can be maximized by developing product innovations to beused as the latest breakthroughs, as concrete evidence at the end of 2017 PT. Investree Radhika Jaya has succeeded in turning their peer to peer $(P 2 P)$ lending product into a leading platform for distributing loans in Indonesia of around 350 billion rupiah. This study uses a qualitative descriptive analysis using techniques to collect facts and realities in the development of shariabased financial technology at PT. Investree. The purpose of this research is to determine the implementation or realization and development of technology-based financing service products by prioritizing sharia principles that make PT. Investree as the object of this research.
\end{abstract}

Keywords: sharia fitech, Investree, financing services. P2P Lending

\begin{abstract}
Abstrak
Kini produk layanan pembiayaan atau lending (crowdfunding dan P2P Lending) pada fintech telah hadir dengan menerapkan prinsip syariah yang mengacu pada fatwa DSN-MUI yang menjadi tolak ukur serta OJK dan DPS sebagai pengawas dalam strategi pengembangannya, seperti pada start-up Investree yang berperan sebagai platform penawaran solusi dalam dunia perbisnisan secara online kepada para pelaku UKM dengan tujuan memperkuat perekonomian negara. Start up investree juga selalu meningkatkan kinerjanya agar lebih maksimal dengan mengembangkan inovasi produk untuk dijadikan sebagai terobosan terbaru, sebagai bukti nyata di akhir tahun 2017 PT. Investree Radhika Jaya telah berhasil merealisasikan produk peer to peer (P2P) lending mereka menjadi sebuah platform terdepan yang menyalurkan pinjaman di
\end{abstract}


Nazela Fardana: Implementasi Produk Layanan... 251

Indonesia sekitar 350 milyar rupiah. Penelitian ini menggunakan analisa deskriptif kualitatif dengan menggunakan teknik mengumpulkan fakta maupun keadaan realita dalam perkembangan financial teknologi berbasis syariah pada PT. Investree. Tujuan dari dibuatnya penelitian ini adalah untuk mengetahui pelaksaan atau realisasi dan perkembangan produk layanan pembiayaan berbasis teknologi dengan mengedepankan prinsip syariah yang menjadikan PT. Investree sebagai objek dalam penelitian ini.

Kata kunci: fitech syariah, Investree, layanan pembiayaan. P2P Lending

\section{Pendahuluan}

Revolusi industri 4.0 membawa banyak perubahan terhadap dunia tidak hanya persaingan dalam bidang bisnis secara tatap muka tetapi juga dalam dunia bisnis berfundamen software, web, maupun penggunaaan internet dalam kehidupan sehari- hari, begitu pula dengan dunia ekonomi syariah yang juga mengalami perkembangan pesat. Fintech Syariah muncul di indonesia sejak 2018 hingga saat ini dan terus mengalami peningkatan yang sangat signifikan. Fintech syariah hadir menjawab kebutuhan umat muslim yang menginginkan kegiatan transaksi halal bebas unsur riba dan diberikan sesuai ketentuan-ketentuan islam. Hampir semua orang menggunakan fintech syariah sebagai pilihan yang tepat untuk kemudahan bertransaksi, tidak hanya umut muslim saja yang menggunnakan layanan financial teknologi berbasis syariah ini, tetapi umat non-muslim juga bisa menggunakan berbagai layanan dari finacial teknologi syariah. Beehive adalah fintech syariah yang pertama di dunia yang berasal dari negara UEA tepatnya di kota Dubai pada tahun 2014 silam, startup ini mendapatkan sertifikat pertama dengan memakai produk peer to peer lending marketplace dan karena startup beehive, fintech syariah telah banyak menjalar dan berkembang ke berbagai negara.

Jenis transaksi yang disediakan oleh layanan fintech syariah (Apriyani 2018) yakni:

a. Investment dan risk management

layanan fintech yang termasuk pada kategori ini adalah, robo advice, e-trading dan insurance.

b. Payments, clearing, dan settlement

Layanan fintech yang termasuk dalam kategori ini adalah mobile payment (misal: P2P transfer, apple/samsung).

c. Deposits, lending, dan capital raisting

layanan fintech yang termasuk pada kategori ini adalah crowdfunding dan juga peer to peer (P2P Lending). 
Semua kegiatan transaksi pada fintech syariah telah diawasi dan diatur oleh OJK dan DPS yang mengeluarkan fatwa DSN-MUI nomor 117/DSN-MUI/II/2018 mengenai layanan pembiayaan berbasis teknologi yang berlandaskan pada prinsip syariah yang memiliki akses pendanaan dengan mudah, cepat, dan sangat efisien.

Investree berperan penting untuk menjalankan peer to peer market place (https://investree.id/how-it-works n.d.) (wadah untuk mempertemukan pemodal dengan oraang yang membutuhkan modal), seperti pusat dari perbelanjaan yang bertugas menyediakan sebuah wadah eksklusif untuk para seller dan buyer agar saling bertemu dan melakukan transaksi serta memilah, menganalisa hingga menyetujui aplikasi yang berfokus pada pinjamaan yang diajukan peminjam supaya menghasilkan pembiayaan yang berkwalitas untuk ditawarkan pada pendana.

Di negara indonesia layanan fintech sendiri termasuk salah satu inovasi dari perkembangan berbasis teknologi financial, sehingga NDRC mengartikan konsep dari fintech dengan harapan kemudahan, aman, dan juga layanan pembiayaan modern untuk masyarakat. Maka dari itu penelitian ini akan membahas tentang pelaksanaan atau implementasi dari layanan pembiayaan PT. Investree seerta mekanisme dari pembiayaan PT. Investree.

Berdasarkan dari pemaparan latar belakang di attas, maka penulis merumuskan beberapa pokok tujuan yang akan menjadi pembahasan dalam penulisan jurnal ini untuk mengetahui bagaimana implementasi layanan pembiayaan berbasis syariah pada startup Investree, untuk mengetahui bagaimana mekanisme pembiayaan dari PT. Investree dan untuk mengetahui akad yang digunakan oleh PT. Investree agar tercapainya transaksi yang sah.

\section{Kajian Teori}

\section{Crowdfunding}

Crowdfunding adalah sebuah bentuk pendanaan untuk seseorang/pengusaha/UKM yang membutuhkan dana dalam pengembangan usahanya, dimana pendanaan tersebut terkumpul dari beberapa orang. Pendekatan ini memanfaatkan upaya kolektif dari sejumlah individu secara online menggunakansebuah platform atau media sosial crowdfunding, sebagai alat menjangkaunya. Crowdfunding juga adalah salah satu bentuk dari crowdsourcing dan keuangan alternatif yang mulai kembali muncul dan banyak dimanfaatkan orang untuk membantu para pengusaha maupun UKM pemula.

Istilah dan konsep crowdfunding diambil dari istilah serupa yang sudah lebih dulu dikenal luas, yaitu crowdsourcing. Crowdsourcing sendiri menggambarkan proses alih 5 daya (outsource) suatu pekerjaan kepada sejumlah individu, sekerumunan orang (komunitas internet) dan mengandalkan pada aset, sumber daya, pengetahuan atau keahlian mereka (Fauzi Abdillah 
Nazela Fardana: Implementasi Produk Layanan... 253

n.d.). Ada perbedaan mendasar antara crowdsourcing dengan crowdfunding, walaupun keduanya memanfaatkan internet dan media sosial, namun hasil yang diharapkan adalah untuk tujuan yang berbeda. Crowdsourcing mengharapkan umpan balik, ide-ide dan saran untuk kepentingan proyeknya sementara crowdfunding dimanfaatkan untuk mengumpulkan dana demi terlaksananya suatu proyek. Secara garis besar, Crowdfunding adalah metode dalam menghasilkan modal untuk mendanai proyek atau usaha dengan melakukan aktivitas penggalangan dana secara online, serta mengandalkan sebagian besar pada kepercayaan intrinsik orang yang menempatkan hubunga teman, keluarga dan komunitas di jaringan sosial sebagai afinitas masyarakat dan menggambarkan proses alih daya (outsource) yang berupa kumpulan investasi dari ukuran kecil sampai menengah dari individu, perusahaan dan komunitas internet dengan mengandalkan berbagai aset, sumber daya, pengetahuan atau keahlian mereka untuk mendapatkan dana.

Crowdfunding (Chalimah 2018) memiliki empat model berbeda yang dapat memudahkan pemberi dana (funder) dalam membuat keputusan penempatan dana yang terbaik, yaitu crowdfunding berbasis donasi (donation-based crowdfunding) yang tidak memberi imbalan apapun dalam segala kontribusi pemberi dana (funder), crowdfunding berbasis penghargaan (reward-based crowdfunding) yang memberikan imbalan berupa penghargaan atau berbagai hal yang bukan berupa uang atau kepemilikan saham, crowdfunding berbasis ekuitas (equity-based crowd funding) yang memberikan imbalan kepada pemberi dana (funder) berupa kepemilikan saham dan crowdfunding berbasis pinjaman (lend-based crowdfunding) yang memberikan imbalan berupa bunga dalam pinjaman yang diberikan oleh pemberi dana (funder).

\section{2. $P 2 P$ (Peer to Peer Lending)}

Biasa disebut person-to-person lending adalah salah satu crowdfunding berupa praktik pemberian pinjaman dimana si peminjam dan pemberi pinjaman (investor) dipertemukan melalui platform yang disediakan oleh perusahaan P2P. (Darmawansyah 2019)

Di Indonesia sendiri Peer to Peer Landing banyak diminati masyarakat dengan berbagai alasan salah satunya ialah karena kemudahan dan singkatnya waktu pencairan dana, hal ini terbukti dari kenaikan jumlah pinjaman yang disalurkan dari Desember 2018 sampai dengan Oktober 2019 sebesar 200,01\%.

3. Fintech (Finansial Technology)

Bank Indonesia mendefinisikan Financial Technology (Fintech) merupakan hasil penggabungan antara jasa keuangan dengan teknologi yang akhirnya mengubah model bisnis 
dari konvensional menjadi moderat.Transaksi keuangan melalui fintech ini meliputi pembayaran, investasi, peminjaman uang, transfer, rencana keuangan, dan pembanding produk keuangan. Teknologi keuangan atau financial technology (Fintech) melahirkan berbagai modal baru yang lebih praktis bagi konsumen dalam mengakses produk dan layanan keuangan. Keberadaan Financial Technology (Fintech) pun menggugah status quo dan revolusi cara kerja institusi keuangan trandisional. (Rahardjo 2017)

Secara spesifik fintech didefinisikan sebagai aplikasi teknologi digital untuk masalahmasalah intermediasi keuangan. Lebih luas lagi fintech didefinisikan sebagai sebuah industri yang terdiri dari perusahaan-perusahaan yang menggunakan teknologi agar sistem keuangan serta penyampaian layanan keuangan lebih efisien. (Darmawansyah 2019)

Maka jika dilihat dari beberapa definisi tersebut dapat dijelaskan bahwa Fintech merupakan sebuah teknologi yang dimana teknologi tersebut membantu dalam hal keuangan. Sehingga transaksi mengenai keuangan dapat dilakukan dengan mudah karena sudah ada teknologi yang dapat mengatasi kegiatan tersebut.

\section{Fatwa DSN-MUI}

Fintech berasal dari kata "financial" dan "technology" yang berarti model layanan keuangan baru yang dikembangkan melalui inovasi teknologi informasi. Sedangkan menurut Fatwa Dewan Syariah Nasional N0.117/DSN-MUI/II/2018 tentang Layanan Pembiayaan Berbasis Teknologi Informasi Berdasarkan Prinsip Syariah. Peraturan ini menjelaskan tentang penyelenggaraan pembiayaan yang mempertemukan atau menghubungkan pemberi pembiayaan dengan penerima pembiayaan dalam rangka melakukan akad pembiayaan sesuai dengan prinsip syariah melalui sistem elektronik dengan menggunakan jaringan internet (Nurhikmah n.d.). Fintech atau yang disebut teknologi finansial memiliki berbagai macam jenisnya, sebagaimana yang diatur dalam Peraturan Bank Indonesia ada empat jenis fintech yang saat ini sedang berkembang pesat di Indonesia. Salah satu diantaranya adalah Peer To Peer Lending. Pembiayaan ini ada yang konvensional dan ada yang juga syariah. Peer To Peer Lending beradasarkan prinsip syariah menggunakan akad Al- Qard untuk pemberian dana talangan dan Wakalah bil ujrah untuk mendapatkan keuntungan dalam transaksinya. Sedangkan untuk pembagian Profit and Loss Sharing sesuai dengan prinsip syariat Islam yang dilakukan para pihak dilakukan atas kesepakatan tanpa memberatkan masing-masing pihak dengan niatan untuk memberikan pertolongan dengan mendapatkan keuntungan tanpa memberatkan.

Saat ini layanan untuk pembiayaan teknologi berdasarkan prinsip syariah di Indonesia sudah memiliki landasan, diatur dalam Fatwa DSN-MUI No:177/DSN- MUI/II/2018 yang berisi enam ketentuan diantaranya tentang ketentuan umum, ketentuan hukum, subjek hukum, ketentuan 
Nazela Fardana: Implementasi Produk Layanan... 255

terkait pedoman umum layanan, model layanan, dan ketentuan terkait mekanisme dan akad. Peraturan tersebut berguna untuk mengatur bagaimana cara kerja atau pembuatan layanan pinjam meminjam berbasis teknologi berjalan dengan benar (Nurhikmah n.d.).

\section{Metode Penelitian}

Dalam penulisan jurnal ini, metode penelitian yang digunakan ialah metode penelitian kualitatif. Yang mana menghasilkan data deskripif berupa kata-kata tertulis dari peneliti. Data yang diperoleh diambil dari hasil studi literatur yang sumbernya berupa buku, jurnal, karya ilmiah maupun web resmi yang relevan dan terpercaya sesuai topik pembahasan jurnal yaitu Implementasi Pembiayaan Syariah berbasis Fintech di PT. Investree. Adapun langkah-langkah yang penulis lakukan dalam penulisan jurnal ini ialah yang pertama, penulis mengumpulkan segala sumber yang berkaitan dengan pembiayaan syariah berbasis fintech yang terdapat pada PT. Investree, baik itu berasal dari buku, jurnal, karya ilmiah dan website. Kemudian penulis menulis apa yang sesuai dengan topik dari berbagai sumber tersebut. Terakhir, penulis menggabungkan data dari semua sumber yang diperoleh menjadi satu dengan menambah opini pribadi dan menuliskannya.

\section{Hasil Pembahasan}

\section{Produk Pembiayaan Usaha Berbasis Peer to Peer Lending di Investree}

Investree (PT Investree Radhika Jaya) merupakan pionir peminjaman modal peer to peer lending berupa marketplace yang dapat menghubungkan peminjam (borrower) dengan pemberi pinjaman (lender) di seluruh Indonesia. Pembiayaan peer to peer lending yang ditawarkan oleh Investree terdiri dari:

a. Pembiayaan Tagihan atau invoice financing merupakan pembiayaan pendanaan yang dilakukan dengan cara memberikan pinjaman tagihan yang sedang berjalan sebagai sumber pembiayaan oleh peminjam (borrower) (Rahayu n.d.). Dengan mekanisme pemberi pinjaman (lender) akan meminjamkan dana berupa modal kerja bagi peminjam yang memiliki hubungan business-to- business dengan perusahaan dan latar belakang keadaan keuangan yang baik dan mumpuni serta dirancang dengan menggunakan skema syariah melalui. akad al-qardh untuk pemberian dana talangan dan akad wakalah bil ujrah untuk mendapatkan keuntungan atau ujrah (Aguspriyani n.d.). 
b. Online seller financing sharia (pembiayaan modal kerja). Sharia online seller financing adalah pembiayaan modal kerja (online seller financing) untuk online dan offline seller yang telah memiliki toko aktif di platform e-commerce rekanan Investree dengan mengunakan prinsip syariah (https://www.investree.id n.d.).

c. Buyer Financing, adalah produk pinjaman modal kerja yang ditujukan kepada para perusahaan UKM yang merupakan pembeli grosir di korporat ritel besar. Seringkali terhadang kebutuhan modal, UKM bisa memperoleh pinjaman untuk memenuhi kebutuhan stok barang dengan lebih cepat dengan menyertakan bukti pemesanan (purchase order) dari korporat ritel terafiliasi. Dana dari para Lender di Investree akan langsung disalurkan kepada korporat ritel terafiliasi untuk membayarkan pesanan stok barang (https://www.investree.id n.d.).

d. Working Capital Term Loan, adalah produk pinjaman modal kerja yang ditujukan bagi UKM-UKM yang memiliki model bisnis yang unik, seperti menerima pembayaran melalui transfer bank/pembayaran digital, bekerja sama dengan Penyedia Jasa Logistik, menggunakan aplikasi sistem kasir (Point of Sales), dan memiliki kontrak/SPK yang sedang berjalan. Catatan penjualan perusahaan dari Agen Pembayaran Online dan/atau Penyedia Jasa Logistik akan dijadikan dasar penilaian credit-scoring Investree atas perusahaan Anda (https://www.investree.id n.d.).

\section{Akad Pembiayaan Pada PT. Investree a. Akad Al-Qard}

Qard berasal dari kata Qarada yang merupakan sinonim dari kata qath'a yang bermakna memotong. Memiliki arti demikian dikarenakan orang yang memeberi hutang memotong sebagaian dari harta untuk diberikan kepada orang yang menerima utang (Muslich 2010). Qard merupakan pinjaman uang, pinjaman qard biasanya diberukan oleh suatu pihak (bank/lembaga) kepada nasabahnya sebagai fasilitas pinjaman talangan. Dalam perjanjian Qard, pemberi pinjaman memberikan pinjaman kepada pihak nasabah dengan ketentuan bahwa penerima akan mengembalikan pinjamana sesuai dengan jangka waktu yang telah diperjanjikandengan jumlah yang sama dengan pinjaman yang diterima (Ismail 2011).

Akad Al-Qard ini diterapkan pada PT. Investree pada praktek pembiayaan yang mereka sediakan. Penerapan akad Qard pada PT. Investree pada Pembiayaan Usaha Syariah yang dikenal dengan Pembiayaan tagihan atau Invoice Financing Syariah, Invoice Financing Syariah merupakan produk yang bekerja dengan cara menjamin invoice, sebuah tagihan atas barang atau jasa yang telah diberikan oleh payor untuk mendapat pembiayaan dari lender (Pemberi Pinjaman). Pada produk ini akad Al-Qard 
Nazela Fardana: Implementasi Produk Layanan... 257

diterapkan sudah sesuai dengan fatwa DSN-MUI No.117/DSN-MUI/II/2018 yaitu pembiayaan dalam bentuk jasa pengurusan penagihan piutang (Darmawansyah 2019).

Adanya akad Al-Qard memberikan manfaat bagi masyarakat diantaranya membantu nasabah yang kesulitan dengan memberi dana talangan jangka pendek. Meningkatkan loyalitas masyarakat kepada bank syariah, mengalihkan nasabah dari keterikatan dengan rentenir (Ismail 2011).

\section{b. Akad Wakalah Bil Ujrah}

Al-Wakalah diartikan sebagai pelimpahan kekuasaan seseorang kepada orang lain dalam menjalankan amanat tertentu. Sedangkan akad Wakalah Bil Ujrah adalah yang disertai dengan imbalah berupa ujrah. Salah satu produk yang dikeluarkan oleh PT. Investree menggunakan akad Wakalah Bil Ujrah yang mana akad ini sebagai dasar ketika pemberi pinjaman (Lender) mengabil keuntungan agar terhindar dari riba. Sebelumnya pemberi pinjaman (Lender) telah mengurus dokumen penjualan atau usaha payor,

kemudian berdasarkan jasa tersebut lander berhak menerima piutang dan balas jasa atau ujrah. Ujrah disepakati pada saat akad dan juga telah ditentukan oleh pihak investree dalam bentuk nominal, bukan dalam bentuk presentase yang dihitung dari pokok piutang (Sri Maulidia 2020).

\section{c. Akad Mudharabah}

Pembiayaan mudharabah erupakan akad pembiayaan antara shahibil maal dengan nasabah (mudharib) untuk melaksanakan kegiatan usaha, yang mana shahibul maal memberikan modal sebanyak 100\% dan nasabah menjalankan usahanya (Ismail 2011). PT. Investree menerapkan akad mudharabah pada produk pembiayaan modal kerja (Online seller financing sharia).

Shariah online seller merupakan pembiayaan modal kerja untuk online maupun offline seller yang sudah memiliki toko aktif di platform e-commerce. Dengan penerapan akad mudharabah dan wakalah, jangka waktu angsuran yang diberikan oleh Shariah online seller selama 12 bulan yang diangsur tiap bulannya, produk pembiayaan ini sudah sesuai dengan Fatwah DSN-MUI No. 117/DSN-MUI/II/2018 yakni tentang pembiayaan yang diberikan kepada pelaku usaha yang melakukan transaksi jual beli online pada 
penyedia layanan pedagangan berbasis teknologi informasi yang telah menjalin kerjasama dengan penyelenggara.

\section{Implementasi Layanan Pembiayaan Fintech Syariah pada PT. Investree}

Investree merupakan perusahaan teknologi finansial di Indonesia yang bergerak di bidang online marketplace yaitu mempertemukan orang yang memiliki kebutuhan dana dengan orang yang memiliki kelebihan dana dan bersedia menginvestasikan dananya. Dalam hal biaya, investree membebaskan biaya pendaftaran maupun pengajuan pembiayaan kepada para konsumennya. Beban biaya hanya dikenakan ketika pembiayaan berhasil didanai oleh para pendana. Begitu juga dengan pendana, hanya menerima pokok pendanaan dan imbal hasil berupa ujrah wakalah sebagai jasa penagihan yang dibayarkan oleh Borrower (Sri Maulidia 2020).

PT. Investree merupakan perusahaan layanan pembiayaan yang bergerak pada kategori Peer- to-Peer Lending (P2PL). Investree adalah sebuah marketplace finansial, yang menyediakan layanan perantara untuk proses peer-to-peer lending. Investree tidak berpartisipasi dalam aktivitas pinjam meminjam. Akan tetapi, Investree hanya menyediakan platform untuk memfasilitasi prosesnya, administrasi akun borrower dan lender.

Produk dari startup investree peer to peer lending syariah saat ini kebanyakan dana pinjamannya maupun pendanaan syariahnya di arahkan oleh perseroan untuk disalurkan sebagai invoice financing. Sektor pertama yang mendapatkan produk pendanaan paling besar disalurkan oleh pihak Investree kepada para pelaku UKM sebanyak $\pm 74 \%$ yang sedang menjadi supplier di perusahaan-perusahaan pelat merah, saat ini PT. Investree hanya menyalurkan pendanaannya kepada ukm yang menjadi vendor di BUMN, BUMD dan perusahaan-perusahaan swasta terbuka, karena kekhawatiran akan pendanaan yang bermasalah (macet) hingga gagal bayar dan supaya resiko tersebut termitigasi. Untuk pendanaan ini dari pihak investree, produk P2P leending syariah hanya menyalurkan pinjaman maksimal sebesar 2 milyar rupiah atau sekitar

$80 \%$ nilai tagihan (invoice) dalam jangka waktu 6 bulan.

Sektor kedua yang mendapatkan pendanaan terbesar adalah modal kerja yang produktif dengan prosentase porsi market 13\%. Sifat dari peminjaman ini adalah kontrak based financing, ruguler loan, atau merchant cash advance. Pinjaman untuk pendanaan sektor ini sebesar maksimal $80 \%$ kontrak, atau setara dengan2 milyar rupiah dalam jangka waktu 24 bulan. Sektor terbesar yang ketiga adalah pembiayaan 
Nazela Fardana: Implementasi Produk Layanan... 259

reseller dengan porsi $6 \%$ dari portofolio (pinjaman dana untuk pemasokan barang oleh distributor) pinjaman ini bisa mencapai $100 \%$ dari nilai pesanan pembelian atau setara dengan 2 milyar rupiah dalam jangka waktu maksimal 12 bulan. Sisanya mencangkup portofolio produk obligasi pemerintah yang sampai 6\%, dan pembiayaan toko online mencapai $1 \%$. Tak hanya itu startup investree juga menyumbang fasilitas pinjaman sebesar 5,82 triliun rupiah sejak startup Invstree didirikan. Saat ini prosentase tingkat keberhasilan bayar 90 hari (TKB90) sebesar 99,71\%. (https://finansial.bisnis.com/read/20200609/231/1250513/mayoritas-pembiayaan-syariahinvestree- disalurkan-ke-anjak-piutang n.d.)

Pada tahun 2017 silam perusahaan Investree meluncurkan terobosan baru hasil inovasi produk pembiayaan berbasis syariah yakni invoice financing syariah dan online seller financing syariah yang mana kedua inovasi produk pembiayaan tersebut telah lulus sertifikasi pada OJK dan DPS. Produk tersebut adalah online seller financing syariah dan invoice financing syariah. Berikut uraiannya: (Darmawansyah 2019)

1) Online seller financing syariah

Online seller financing syariah atau disebut dengan pembiayaan modal kerja, yakni produk pembiayaan yang dipergunakan untuk seller online dan juga offline dengan syarat mempunyai toko aktif pada platform e-commerce rekanan Investree yang berlandaskan prispis syariah (memakai akad murabahah dan wakalah) untuk skema pembayarannya dapat diangsur hingga 12 bulan. Produk online seller financing ini telah diatur dalam fatwa DSN- MUI No. 117/DSN-MUI/II/2018 karena produk ini hampir sama dengan online seller yaitu pembiayaan yang diberi kepada pengusaha yang sedang melakukan transaksi secara online kepada e- commerce atau marketplace yang sudah menjalin kerjasama.

2) Invoice financing syariah

Invoice financing atau disebut dengan pembiayaan tagihan, yakni produk untuk membiayai yang telah dijamin oleh invoice, untuk skema pembayarannya menggunakan akad al-qard (pinjaman yang dikembalikan dengan jumlah yang sama) guna memeberikan dana pinjaman serta menggunakan akad wakalah bil-ujrah (pemberian kuasa untuk pada pihak lain untuk dikelola) guna untuk mendapatkan profit. Mekanisme pembiayaan invoice financing yaitu dengan cara meminjamkan tagihan dari barang maupun jasa yang sudah diberikan payor dengan maksud agar memperoleh 
pembiayaan dari pihak lender. Pihak payor akan membayar invoice (tagihan) kepada lender pada masa akhir periode, dan pihak lender akan mendapatkan pokok pendanaan dan juga pendapatan wakalah dari jasa pengurusan dokumen penagihan. produk ini juga telah diatur dalam Fatwa DSN MUI Nomor 67/DSN- MUI/III/2008 yakni tentang "Anjak Piutang Syariah" tanggal 6 Maret 2008 (https://investree.id/syariah/faq-syariah/general n.d.).

Untuk memaksimalkan kinerjanya, startup Investree syariah selalu mempersiapkan matang-matang beberapa strategi dengan tujuan untuk meningkatkan investor dari beberapa institusi dengan kisaran persiapan 60\%, karena saat ini bank-bank syariah pelat merah mengalami marger yang menjadi Bank Syariah Indonesia, maka dari itu Investree ingin berkolaborasi dengan Bank Syariah Indonesia.

\section{Mekanisme Peer to Peer (P2P) di PT. Investree}

PT. Investree Radhika Jaya bergerak pada layanan pembiayaan berbasis teknologi/finansial teknologi berbasis Peer to Peer $(P 2 P)$ lending. Perusahaan yang melakukan pembiayaan dengan Peer to Peer $(P 2 P)$ lending merupakan perusahaan yang mempertemukan para pemberi pinjaman (investor) dengan para pencari pinjaman (borrower). Selain itu, Peer to Peer (P2P) lending juga menjadi tempat para investor untuk mengetahui lebih mendalam bahwa para pencari pinjaman yang dipasang di website Peer to Peer (P2P) lending adalah peminjam dengan kualitas terbaik (https://finansial.bisnis.com/read/20200609/231/1250513/mayoritas-pembiayaan-syariahinvestree- disalurkan-ke-anjak-piutang n.d.).

Terdapat alur pelaksanaan pembiayaan syariah berbasis teknologi informasi (fintech) secara umum dan mekanisme Peer to Peer (P2P) di PT. Investree secara lebih rinci, diantaranya sebagai berikut:

\section{Keterangan:}

1. Penerima pembiayaan melakukan registrasi ke Investree, lalu Investree memeriksa data penerima pembiayaan serta tim risk akan melakukan analisa dari KTP, NPWP (individu/perorangan), akte perusahaan (badan hukum/perusahaan), jika datanya sesuai akan diberikan kontrak (Apriyani 2018).

2. PT. Investree memasukkan para penerima pembiayaan ke website untuk diperlihatkan kepada calon pemberi pembiayaan.

3. Pemberi pembiayaan memilih calon-calon penerima pembiayaan dan menginvestasikan dananya ke calon penerima pembiayaan melalui PT. Investree. 
Nazela Fardana: Implementasi Produk Layanan... 261

4. PT. Investree menyalurkan dana dari pemberi pembiayaan kepada penerima pembiayaan.

Untuk lebih rincinya, terdapat 2 mekanisme Peer to Peer (P2P) di PT. Investree diantaranya (Wiyono 2020):

a. Sebagai lender (pemberi pinjaman)

Sebagai lender ada beberapa mekanisme dan layanan yang perlu diperhatikan. Pertama, syaratnya adalah WNI atau WNA dengan usia minimal 17tahun, dengan dokumen KTP dan NPWP. Untuk WNA paspor dan rekening bank di Indonesia. Kedua, nilai minimal pembiayaan adalah 5 juta dengan kelipatan 1 juta. Nilai maksimal pembiayaan pada setiap pembiayaan adalah 100 juta. Ini bertujuan untuk mendorong lender melakukan diversifikasi pembiayaan. Termasuk mengurangi risiko pembiayaan jika borrower mengalami gagal bayar atau wanprestasi.

Ketiga, tentang keamanan. Dijelaskan bahwa Investree menjunjung tinggi nilai transparansi dengan mencantumkan informasi seputar borrower, serta syarat dan ketentuan pembiayaan di marketplace.

Investree juga melakukan analisis, seleksi, dan persetujuan terhadap seluruh calon borrower beserta pembiayaan yang diajukan dengan menggunakan sistem credit-scoring modern, sehingga hanya pembiayaan berkualitas tinggi yang akan ditawarkan kepada lender. Untuk produk invoice financing, Investree menegaskan hanya akan menerima invoice dari perusahaan/institusi/lembaga yang kredibel, dan seluruh lalu lintas pendanaan akan dikelola oleh Investree bekerjasama dengan bank rekanan.

Sejak tanggal 31 Mei 2017 lalu, Investree telah terdaftar dan diawasi oleh OtoritascJasa Keuangan (OJK) dan khusus untuk layanan Investree Syariah, sejak tanggal 23cAgustus 2017, Investree telah memperoleh surat rekomendasi penunjukan Tim Ahli Syariah dari Dewan Syariah NasionalMajelis Ulama Indonesia (DSNMUI) melalui Surat Nomor U-492/DSN- MUI/VIII/2017. Namun demikian, dengan alasan komitmen menjaga kerahasiaan identitas dan data pribadi borrower, hanya informasi demografis dan finansial yang akan diberitahukan kepada lender. Informasi tersebut dapat digunakan untuk menganalisis tingkat risiko pendanaan dari pembiayaan yang ditawarkan.

Untuk pembiayaan syariah, Lender tidak akan menerima ujrah atas keterlambatan pembayaran dari Borrower. Dan risiko terbesar yang mungkin terjadi dalam peer-to-peer 
financing adalah lender tidak menerima kembali dana yang disalurkan dan imbal hasil atau ujrah atas jasa wakalah dikarenakan kegagalan pembayaran. Jika borrower mengalami kegagalan pembayaran seperti tersebut, Investree akan segera mengambil tindakan untukmelindungi kepentingan lender melalui pencairan jaminan.

b. Sebagai borrower ( penerima pinjaman)

Sebagai borrower ada beberapa mekanisme dan layanan yang mesti diperhatikan. Pertama, melakukan pendaftaran secara online melalui situs resmi Investree, lalu akan diminta untuk memberikan beberapa rincian pribadi termasuk invoice dan dokumen legalitas perusahaan yang masih berlaku. Kemudian aplikasi pembiayaan akan dianalisis dan diseleksi melalui sistem credit-scoring. Setelah aplikasi tersebut disetujui, pembiayaan yang diajukan akan ditampilkan di marketplace Investree.

Kedua, untuk menjaga prinsip Pembiayaan Syariah agar tetap pada koridornya, maka tidak semua invoice dapat diterima di Investree Syariah. Invoice yang berasal dari industri rokok, minuman keras, obat terlarang, babi, perjudian, prostitusi, hotel yang belum syariah, dan kegiatan yang mengandung spekulasi bukan merupakan pasar sasaran dari Investree Syariah. Jenis invoice yang menjadi prioritas adalah yang ditujukan kepada Payor berupa perusahaan besar, contohnya perusahaan multinasional, institusi yang terdaftar di bursa saham, atau instansi pemerintahan. Nantinya, setiap invoice yang diajukan akan dianalisis, diseleksi, dan disetujui berdasarkan sistemcreditscoring modern (Wiyono 2020).

Ketiga, biaya. tingkat biaya akan bergantung pada profil setiap pembiayaan; ditetapkan berdasarkan proses analisis kredit oleh Investree. Selain itu, biaya yang dikenakan adalah biaya wakalah, biaya marketplace, dan biaya notaris untuk pengikatan jaminan termasuk denda jika nantinya terjadi keterlambatan. Semua biaya akan diinformasikan kepada Borrowersehingga tidak ada yang disembunyikan.

Keempat, jangka waktu dan besaran. Investree akan memfasilitasi Pembiayaan Syariah maksimal $80 \%$ dari nilai invoice atau maksimal Rp 2.000.000.000 untuk setiap invoice. Jangka waktu Pembiayaan Syariah akan disesuaikan dengan jatuh tempo invoice atau maksimum 6 bulan disertai dengan pertimbangan dan analisis dari Investree.

\section{Mekanisme Crowdfunding}

a) Mekanisme Crowdfunding Secara Umum 
Nazela Fardana: Implementasi Produk Layanan... 263
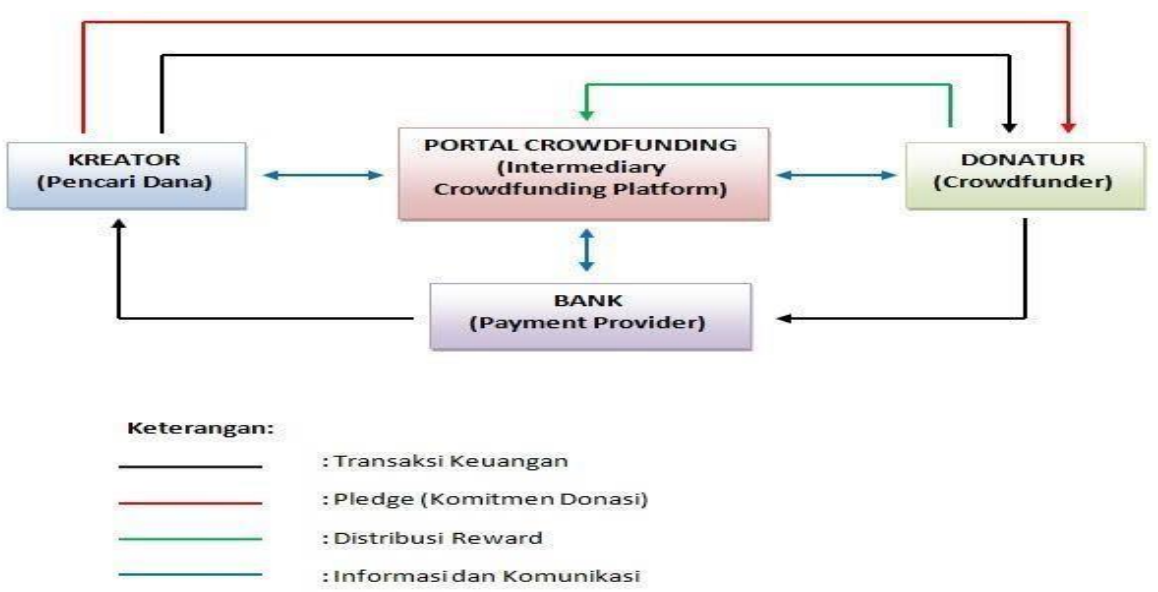

Hal pokok yang harus ada dalam mekanisme crowdfunding adalah individu pencari dana, portal crowdfunding (PT. Investree) sebagai penghubung (intermediary), dan masyarakat sebagai donatur. Proses crowdfunding dimulai dengan individu pencari dana melakukan registrasi pada portal crowdfunding secara online. Setelah melakukan registrasi, pencari dana mengajukan proposal kepada portal crowdfunding. Portal crowdfunding akan melakukan seleksi atas proposal yang dikirimkan. Apabila diterima, maka proyek akan ditampilkan pada halaman portal dan individu pencari dana tersebut dinamakan kreator (Fauzi Abdillah n.d.)

Selama periode proyek tersebut ditampilkan pada halaman portal crowdfunding (umumnya antara 30-90 hari), baik pihak portal crowdfunding dan kreator melakukan kampanye dan sosialisasi melalui media sosial. Masyarakat yang tertarik dapat berpartisipasi dengan menjadi donatur. Dana kemudian dikirimkan dengan cara transfer bank ke rekening milik portal crowdfunding. (Nurhikmah n.d.)

Metode penyaluran dana pada crowdfunding di Indonesia baru mengenal dan memanfaatkan metode transfer bank. Apabila target dana terkumpul, maka dana akan ditransfer oleh portal crowdfunding kepada kreator proyek dan sebaliknya, bila dana tidak mencapai target, maka akan dikembalikan kepada donatur atau donatur diberikan pilihan untuk mengalihkan dana kepada proyek lain yang juga sedang ditampilkan pada halaman portal crowdfunding.

\section{Kesimpulan}

Dari tulisan diatas dapat disimpulkan bahwa fintech adalah penggunaan teknologi informasi dalam sistem keuangan untuk meningkatkan efektivitas dan efisiensi kegiatan layanan 
keuangan untuk memecahkan masalah-masalah intermediasi keuangan. Dengan adanya fintech sangat memudahkan masyarakat untuk melakukan pinjaman. Dibantu dengan aadanya fintech syariah seperti Investree ini banyak UKM yang dapat menggunakan platform tersebut untuk mewujudkanusaha yang sedang mereka inginkan. Karena pada era modern saat ini semua orang membutuhkan platform pembiayaan yang lebih praktis dan tentunya sangat mudah digunakan kapan saja. Pada Investree tersedia beberapa produk pembiayaan yang dapat dipilih oleh masyarakat sesuai dengan kebutuhan yang sedang msyarakat butuhkan. Dari semua produk pembiayaan yang tersedia di Investree tentunya memiliki keuntungan dan kegunaan yang berbeda-beda oleh karena itu masyarakat harus selektif dalam memilih dan menggunakan produk pembiayaan yang ada pada platform Investree.

\section{Daftar Pustaka}

Aguspriyani, Darmawansyah Dan. "Implementasi Fintech Syariah Di Pt Investree Ditinjau Berdasarkan Fatwa Dsn-Mui No: 117/Dsn-Mui/Ii/2018 Tentang Layanan Pembiayaan Berbasis Teknologi Informasi Berdasarkan Prinsip Syariah." N.D.

Apriyani. "Penerapan Layanan Pembiayaan Teknologi Informasi Berbasis Syariah Berdasarkan Fatwa Dsn-Mui No. 117/Dsn- Mui/Ii/2018 (Studi Pt. Investree Radhika Jaya)." 2 (2018).

Chalimah, Claudia Villahi. "Model Penjelas Keputusan Berdonasi Melalui Layanan Pendanaan Berbasis Financial Technology (Crowdfunding)." Jurnal Universitas Islam Indonesia, 2018: 5 .

Darmawansyah, Trisna Taufik Dan Yani Aguspriyani. "Implementasi Fintech Syariah Di Pt. Investree." Jurnal Ekonomi Dan Bisnis Islam 3 (Oktober 2019): 220.

Fauzi Abdillah, Endang Danila. "Crowdfunding: Demokratisasi Akses Keuangan Dalam Mendukung Aksi Sosial Mahasiswa." Jurnal Departemen Pendidikan Kewarganegaraan Sekolah Pascasarjana Universitas Pendidikan Indonesia, N.D.

"Https://Finansial.Bisnis.Com/Read/20200609/231/1250513/Mayoritas-PembiayaanSyariah- Investree- Disalurkan-Ke-Anjak-Piutang." N.D. 
Nazela Fardana: Implementasi Produk Layanan... 265

"Https://Investree.Id/How-It-Works." N.D.

"Https://Investree.Id/Syariah/Faq-Syariah/General."

N.D. "Https://Www.Investree.Id." N.D.

Ismail. Perbankan Syariah. Jakarta: Prenadamedia, 2011.

Muslich, Ahmad Wardi. Fiqh Muamalat. Jakarta: Amzah, 2010.

Nurhikmah, Zaini Abdul Malik, Shindu Irwansyah. "Tinjauan Fatwa DSN No.117/DSNMUI/II/2018 tentang Layanan Fintech Berdasarkan Prinsip Syariah Terhadap Layanan Pinjaman Online di PT.Alami Fintek Sharia." Jurnal Prodi Hukum Ekonomi Islam, Fakultas Syariah Universitas Islam Bandung 6 (n.d.): 2.

Rahayu, Mukhtar dan. "Analisis Pendanaan Modal Umkm Melalui Financial Technology Peer To Peer Lending (P2P)." n.d.

Sri Maulidia, Ahmad Hasan, Masyitah Umar. "Implementasi Akad Qard dan Wakalah Bil Ujrah pada PlatformFintech LendingSyariah ditinjau berdasarkan Peratutan Otoritas Jasa Keuangan(OJK) danFatwah DSN-MUI." Al-Tijary, Jurnal Ekonomi dan Bisnis Islam 5 (2020): 180.

Wiyono, Teguh. "Mekanisme dan Layanan Peer-to-Peer Lending Syariah Perspektif Ekonomi Islam (Studi Analisis pada 13 Fintech Syariah yang Terdaftar di Otoritas Jasa Keuangan Per 19 Februari 2020)." Tesis IAIN Ponorogo, 2020: 74-76. 